\title{
Short communication: The effect of 4 antiseptic compounds on umbilical cord healing and infection rates in the first 24 hours in dairy calves from a commercial herd
}

\author{
A. L. Robinson, ${ }^{1}$ L. L. Timms, K. J. Stalder, and H. D. Tyler \\ Department of Animal Science, lowa State University, Ames 50011
}

\begin{abstract}
The objective of this study was to compare the effect of 4 antiseptic compounds on the healing rate and incidence of infection of umbilical cords in newborn calves $(\mathrm{n}=60)$. Late gestation Jersey cows were monitored at a commercial farm (Sioux Jersey, Salix, IA) and newborn purebred $(\mathrm{n}=30)$ and crossbred $(\mathrm{n}=30)$ calves were obtained within $30 \mathrm{~min}$ after birth. Calves were alternately assigned by birth order to 4 treatment groups: $7 \%$ tincture of iodine, $0.1 \%$ chlorine created using a novel chlorine disinfectant technology, chlorohexidine gluconate $4.0 \% \mathrm{wt} / \mathrm{vol}$, and $10 \%$ trisodium citrate. Prior to dipping (within 30 min of birth), diameter of the umbilical cords (as an indicator of cord drying and healing) were determined using digital calipers. In addition, as an indicator of umbilical infections, surface temperature of the umbilical stump (along with a reference point at the midpoint of the sternum) was determined using a dual-laser infrared thermometer. These measurements were all repeated at $24 \pm 1 \mathrm{~h}$ of age. All data were analyzed using mixed model methods. All models included fixed effects of breed (Jersey or Jersey cross), sex (bull or heifer), and treatment. Fixed effect interactions were not included in the statistical model due to the relatively small sample size. No treatment differences were noted for healing rate of umbilical cords. Initially, mean umbilical cord diameter was 22.84 $\pm 3.89 \mathrm{~mm}$ and cords healed to a mean diameter of 7.64 $\pm 4.12 \mathrm{~mm}$ at $24 \mathrm{~h}$ of age. No umbilical infections were noted for calves on any treatment during the course of this study. Mean surface temperature of the umbilical stump was $33.1 \pm 2.2^{\circ} \mathrm{C}$ at birth $\left(1.5 \pm 1.6^{\circ} \mathrm{C}\right.$ higher than the sternal reference temperature), and at $24 \pm 1$ $\mathrm{h}$ of age the mean temperature of the umbilical stump was $33.0 \pm 4.3^{\circ} \mathrm{C}\left(0.5 \pm 1.8^{\circ} \mathrm{C}\right.$ lower than the sternal reference temperature). These data suggest that these
\end{abstract}

Received December 12, 2014.

Accepted April 15, 2015.

${ }^{1}$ Corresponding author: afordyce@iastate.edu antiseptic compounds are equally effective for preventing infections and permitting healing of the umbilical cord when used within 30 min of birth.

Key words: calves, umbilical cord, antiseptic compound

\section{Short Communication}

The umbilical cord serves as a conduit for the blood supply between the fetus and the placenta throughout pregnancy. The cord ruptures during the birth process, leaving an umbilical stump that becomes a potential route for pathogen entry into the newly born calf, increasing the risk of septicemia. Studies indicate that 15 to $20 \%$ of dairy calves in the United States develop umbilical infections (Virtala et al., 1996b), and 1.6\% of calf deaths are related to umbilical infections (USDA, 2010). Umbilical infection also reduces total BW gain during the first $3 \mathrm{mo}$ of life (Virtala et al., 1996a). Careful and consistent umbilical cord care substantially decreases calf mortality. Typically, antiseptic compounds are used to help clean, sanitize, and speed healing of the umbilical stump. The 2 most common choices of antiseptic compounds are $7 \%$ iodine or $4 \%$ chlorhexidine.

Tincture of iodine is most commonly recommended as an antiseptic for disinfecting umbilical cords after birth. The $7 \%$ iodine is mixed in an alcohol base; the iodine concentration is strong enough to kill most pathogens with a short contact time, whereas the alcohol is thought to assist in increasing the rate of drying out of the umbilical stump. Iodine is bactericidal, sporicidal, cysticidal, and virucidal (WHO, 1999). The antiseptic properties begin to decrease approximately $15 \mathrm{~min}$ after dipping, but remain evident for several hours. However, alcohol does not promote drying, is less effective against bacteria than other antimicrobials, and delays cord separation. Therefore, it is not considered acceptable either for cleaning or for routine application to the umbilical stump (WHO, 1999). Federal regulations regarding the sale and storage of $7 \%$ iodine solutions have increased the interest in exploring the effectiveness of alternative antiseptics. 
Chlorhexidine is an excellent choice of antiseptic because it has a broad spectrum of activity against both gram-positive and gram-negative bacteria; in addition, it has a relatively long duration of activity, low toxicity, and typically does not irritate skin to the same extent as iodine (Imdad et al., 2013). Several nonrandomized trials have provided consistent evidence that $4.0 \%$ chlorhexidine can reduce the risk of both umbilical cord and periumbilical infections (Mullany et al., 2003). The high cost of chlorhexidine relative to other antiseptics has limited widespread use in production settings.

New technologies have been developed for use in teat dips. Trisodium citrate is a noniodine dip that was originally designed for presurgical skin preparation but has been redesigned for use as a commercial teat dip. It provides a wide spectrum of germicidal activity and has no-drip properties that may help protect the vulnerable opening at the end of the cord. However, it also contains skin emollients that may slow drying time when used to dip umbilical cords.

Chlorine has been used as a teat dip because it has excellent germicidal properties; however, it can also irritate sensitive tissues and is relatively unstable in solution. However, new technologies have led to the development of a novel formulation of $0.1 \%$ of chlorine that does not damage tissues and retains germicidal properties for extended periods of time. The objective of our study was to compare 4 antiseptic solutions $(7 \%$ iodine, $4 \%$ chlorhexidine, $10 \%$ trisodium citrate, and $0.1 \%$ of chlorine-based products) to determine their effect on umbilical healing and 24-h infection rates in a field trial with dairy calves.

The Iowa State University Animal Care and Use Committee approved this project. Purebred Jersey ( $\mathrm{n}=$ $30)$ and Jersey-cross calves $(\mathrm{n}=30)$ were monitored at a commercial farm (Sioux Jersey, Salix, IA). All calves were obtained within $30 \mathrm{~min}$ after birth. Calves were born in a group calving pen and moved within the first hour to a group calf-holding pen. During the first 24 $\mathrm{h}$ of life, calves were moved to commercial plastic calf hutches at 2 separate facilities (one facility for purebred Jersey heifer calves, the second facility for all other calves). Different bedding substrates were used inside the calf hutches at each facility. Purebred Jersey heifer calves were bedded with pine shavings and limestone powder, whereas crossbred and purebred bull calves were bedded with a combination of pine shavings and straw. All calves were fed pooled maternal colostrum within $3 \mathrm{~h}$ after birth.

Calves were alternately assigned by birth order to 4 treatment groups: 7\% iodine (Qualis Veterinary Products, Des Moines, IA), $0.1 \%$ of chlorine (ECAlogix System, Zurex Pharmagra, Middleton, WI), 4\% chlorhexidine (Hibiclens, Mölnlycke Health Care US, Norcross,
GA), and 10\% trisodium citrate (Zuragen, Zurex Pharmagra). All umbilical cords were dipped within 30 min of birth. Prior to initial dipping, diameter of the umbilical cords (as an indicator of cord drying and healing) were determined using digital calipers. As an indicator of umbilical infections, surface temperature of the umbilical stump (along with a reference point at the midpoint of the sternum) was determined using infrared technology (Dual Laser 50 model 42570, Extech Instruments Corporation, Waltham, MA). These measurements were all repeated at $24 \pm 1 \mathrm{~h}$ of age.

All data were analyzed using mixed model methods (PROC MIXED; SAS Institute, 2008). All models included the fixed effects of breed (Jersey or Jersey cross), sex (bull or heifer), and treatment. None of the fixed effects were significant. Fixed effect interactions were not included in the statistical model due to the relatively small sample size. Significance was declared at $P \leq 0.05$.

Mean diameter of umbilical cords for all calves $(\mathrm{n}=$ 60) was $22.85 \mathrm{~mm}$ at birth and decreased to $7.64 \mathrm{~mm}$ at $24 \mathrm{~h}$ of age. No treatment differences were noted $(P>0.05)$ between dips on healing rate of umbilical cords (Table 1). No umbilical infections occurred in any of the calves on this trial within the first $24 \mathrm{~h}$ of life. The mean surface temperature of the umbilical stump was $33.1 \pm 2.2^{\circ} \mathrm{C}$ at birth $\left(1.5 \pm 1.6^{\circ} \mathrm{C}\right.$ higher than the sternal reference temperature). At $24 \pm 1 \mathrm{~h}$ of age, the mean temperature of the umbilical stump was 33.0 $\pm 4.3^{\circ} \mathrm{C}\left(0.5 \pm 1.8^{\circ} \mathrm{C}\right.$ lower than the sternal reference temperature; Table 1).

Despite the importance of umbilical cord care, very few randomized trials have been conducted to determine optimal cord care in production animal settings. Only a small number of studies have compared cord antiseptics in farm animals. In one epidemiological study, risk of calf mortality was significantly lower following use of chlorhexidine compared with iodine or no cord care; iodine tended to increase mortality risk (WaltnerToews, et al., 1986).

However, the findings of our study indicate that appropriate antimicrobial solutions applied to the umbilical cord within $30 \mathrm{~min}$ of birth are protective against umbilical cord infections and permitted healing in neonatal dairy calves. Our findings confirm and extend the findings from previous studies done by Grover and Godden (2011), which demonstrated the effectiveness of a navel dip (Navel Guard, SCG-Solutions Inc., McDonough, GA) in decreasing the incidence of omphalitis in newborn dairy calves when compared with not dipping navels. No statistical difference was observed between any of the dips tested (Navel Guard, $7 \%$ tincture of iodine, and 0.5 to $2 \%$ iodine solutions) for decreasing the incidence of omphalitis in newborn 
Table 1. Umbilical cord diameter decreased during the first $24 \mathrm{~h}$ of life as healing progressed for all calves (n $=60)$, and rate of healing was not affected by individual treatments $(\mathrm{n}=15 / \text { treatment; } P>0.05)^{1}$

\begin{tabular}{|c|c|c|c|c|}
\hline Item & $\begin{array}{l}7 \% \\
\text { Iodine }\end{array}$ & $\begin{array}{c}4 \% \\
\text { Chlorhexidine }\end{array}$ & $\begin{array}{l}10 \% \text { Trisodium } \\
\text { citrate }\end{array}$ & $\begin{array}{c}0.1 \% \\
\text { Chlorine }\end{array}$ \\
\hline Umbilical diameter at birth (mm) & $23.8 \pm 1.0$ & $21.3 \pm 1.0$ & $22.9 \pm 1.0$ & $23.7 \pm 1.0$ \\
\hline Umbilical diameter at $24 \mathrm{~h}(\mathrm{~mm})^{\prime}$ & $6.7 \pm 0.9$ & $10.1 \pm 1.1$ & $6.8 \pm 0.9$ & $9.0 \pm 0.9$ \\
\hline Stump temperature at birth $\left({ }^{\circ} \mathrm{C}\right)$ & $32.6 \pm 0.7$ & $33.3 \pm 0.5$ & $32.8 \pm 0.6$ & $33.5 \pm 0.6$ \\
\hline Sternal temperature at birth $\left({ }^{\circ} \mathrm{C}\right)$ & $31.6 \pm 0.6$ & $31.9 \pm 0.5$ & $30.6 \pm 0.6$ & $32.3 \pm 0.5$ \\
\hline Stump temperature at $24 \mathrm{~h}\left({ }^{\circ} \mathrm{C}\right)$ & $31.6 \pm 1.1$ & $32.5 \pm 1.2$ & $34.9 \pm 1.0$ & $33.0 \pm 1.0$ \\
\hline Sternal temperature at $24 \mathrm{~h}\left({ }^{\circ} \mathrm{C}\right)$ & $31.7 \pm 1.3$ & $33.3 \pm 1.3$ & $35.3 \pm 1.1$ & $33.9 \pm 1.0$ \\
\hline
\end{tabular}

${ }^{1}$ Sternal temperature was used as a reference point for normal body temperature. Umbilical stump temperatures were higher at birth in all calves $(\mathrm{n}=60)$ due to increased blood flow to that area, but decreased as healing progressed through the first $24 \mathrm{~h}$ of life.

dairy calves. These data, in total, suggest that many disinfectants can be effective as antiseptic compounds when managed effectively (i.e., dipping within $30 \mathrm{~min}$ of birth).

The current study provides a novel way to assess early signs of infection using the surface temperature of the umbilicus area compared with the sternal temperature (as determined using infrared technology). An increase in umbilical stump temperature when compared with the sternal temperature combined with a tender umbilical stump may indicate the presence of an infection. Similar approaches using infrared technology have been used to diagnose infection in human medical applications (Fierheller and Sibbald, 2010). In addition, the use of digital calipers to measure the diameter of the umbilical cord may be useful to assess healing rate of the cord. A decrease in the diameter of the cord indicates that the umbilical cord is healing.

Several management and environmental factors may have affected the association between disinfectants, infection rate, and cord healing. Calves in our study originated from a single farm and were born during the same season, which resulted in very dry environmental conditions that may have enhanced healing rate. In addition, calves were removed from the study at $24 \mathrm{~h}$ of age and differences in infection rate after that time point may have occurred. Future work in this area is needed to determine the efficacy of antiseptics under wet, cold, or contaminated conditions.

Currently, iodine is the most commonly used antiseptic compound in the dairy industry; however, safety concerns exist with the $7 \%$ concentration. If caution is not used during application, iodine can burn tissues on both calves and workers. Chlorhexidine, chlorine, and trisodium citrate are all effective alternatives to iodine without the risk of damage to sensitive tissues. In summary, all 4 dips tested were effective in preventing umbilical infections and permitting healing of the umbilical cord when used within 30 min of birth under clean, dry conditions.

\section{ACKNOWLEDGMENTS}

The authors acknowledge Zurex Pharmagra (Middleton, WI) for the donation of their products and Sioux Jersey (Salix, IA) for allowing access to their facility.

\section{REFERENCES}

Fierheller, M., and R. G. Sibbald. 2010. A clinical investigation into the relationship between periwound skin temperature and local wound infection in patients with chronic leg ulcers. Adv. Skin Wound Care 23:369-379.

Grover, W. M., and S. Godden. 2011. Efficacy of a new navel dip to prevent umbilical infection in dairy calves. Bov. Pract. 45:70-77.

Imdad, A, R. M. Bautista, K. A. Senen, M. E. Uy, J. B Mantaring III, and Z. A. Bhutta. 2013. Umbilical cord antiseptics for preventing sepsis and death among newborns. Cochrane Pregnancy Childbirth Group http://dx.doi.org/10.1002/14651858.CD008635.pub2

Mullany, L. C., G. L. Darmstadt, and J. M. Tielsch. 2003. Role of antimicrobial applications to the umbilical cord in neonates to prevent bacterial colonization and infection: A review of the evidence. Pediatr. Infect. Dis. J. 22:996-1002.

SAS Institute. 2008. SAS/STAT Version 9.2 User's Guide. SAS Institute Inc., Cary, NC.

USDA. 2010. Dairy 2007: Heifer Calf Health and Management Practices on U.S. Dairy Operations, 2007. USDA, Washington, DC.

Virtala, A. M. K., G. D. Mechor, Y. T. Grohn, and H. N. Erb. 1996a. The effect of calfhood diseases on growth of female dairy calves during the first 3 months of life in New York state. J. Dairy Sci. 79:1040-1049.

Virtala, A. M. K., G. D. Mechor, Y. T. Grohn, and H. N. Erb. 1996b. Morbidity from nonrespiratory diseases and mortality in dairy heifers during the first three months of life. J. Am. Vet. Med. Assoc. 208:2043-2046.

Waltner-Toews, D., S. W. Martin, and A. H. Meek. 1986. Dairy calf management, morbidity and mortality in Ontario Holstein herds. IV. Association of management with mortality. Prev. Vet. Med. $4: 159-171$.

World Health Organization (WHO). 1999. Care of the Umbilical Cord: A review of the evidence. Reproductive Health (Technical Support). Maternal and Newborn Health/Safe Motherhood. World Health Organization, Geneva, Switzerland. 